\title{
Activity rhythms and cyclical changes of microhabitat preferences in the intertidal pipefish Nerophis lumbriciformis (Pisces: Syngnathidae)
}

Received: 4 September 2001 / Revised: 4 February 2002 / Accepted: 14 February 2002 / Published online: 5 April 2002

(C) Springer-Verlag and ISPA 2002

\begin{abstract}
As an inhabitant of the intertidal zone, Nerophis lumbriciformis predictably should show a clear rhythmic activity, with its maximum closely correlated with the high tide period, as observed in several other rocky intertidal fish species. We investigated the rhythmic activity patterns of $N$. lumbriciformis and analysed to what extent specific substratum preferences may be linked to water level and, ultimately, to the particular activity rhythm patterns of the fish. To determine N. lumbriciformis substratum preferences, two different experiments were conducted. The first evaluated substratum preferences from among a group of the four most common substrates found in the sample area. The second experiment evaluated the fish's maintenance of that substratum preference, after alteration of the water level in a simulated ebb tide. From the available substrata, N. lumbriciformis displayed a clear preference for algae until the water level began to decrease. Then, the preference radically shifted from algae to boulders. $N$. lumbriciformis showed a clear rhythmic activity, affected by both tidal and circadian periodicity, producing asymmetrical activity peaks. Unlike the rhythms of other rocky intertidal fish species, the maximum activity peaks were not centred at the expected high tide period. The adaptive explanation for the apparently peculiar activity peaks appears to be related to the particular substratum preferences of $N$. lumbriciformis. The detected circatidal period seems, consequently, closely related to small migrations between substrata, whilst the observed increase in diurnal activity, independent of the tidal cycle, may be related to predatory activity, since $N$. lumbriciformis is a visual feeder.
\end{abstract}

Communicated by R. Serrão Santos

N.M. Monteiro $(\bowtie) \cdot$ M.N. Vieira

Department of Zoology and Anthropology,

Faculty of Sciences of the Oporto University,

Praça Gomes Teixeira, 4099-002 Porto, Portugal

e-mail: nmonteir@fc.up.pt

Tel.: +351-22-3401514, Fax: +351-22-3401511

V.C. Almada

ISPA, Rua Jardim do Tabaco, 34, 1149-041 Lisbon, Portugal
Keywords Nerophis lumbriciformis $\cdot$ Rhythmic activity Syngnathidae Substratum preference

\section{Introduction}

Biological rhythmicity, with a periodicity that is correlated with major events in the fluctuating physical environment, is a widespread phenomenon in the living world (Leatherland et al. 1992). A great number of marine organisms show rhythmic activity patterns, which generally consist of movement sequences correlated with environmental variables of daily or tidal periodicity (Gibson 1988, 1992, 1993; Naylor 1988). The ebb and rise of tides, both spatially and temporally, cause drastic changes in the intertidal zone, forcing mobile species, such as fish, to respond to these changes either by looking for shelter (avoiding the harsh emersion conditions) or by completely abandoning the area. Either of these responses may impose a rhythmic periodicity on the individuals' patterns of movement, since they are regularly forced to alter their spatial localisation. Moreover, the extension and frequency of the individuals' displacements will closely depend on the nature of the cycle they are responding to, as well as their own physiological requirements (Gibson 1999).

On shores that experience a large tidal range, certain littoral fish have been shown to possess rhythms of locomotory activity, the peaks of which coincide with the times of high water (Gibson 1965, 1967, 1969). These rhythms are endogenous since they persist for varying lengths of time under constant laboratory conditions (Gerkema 1992; Gibson 1967, 1969). They allow fish to anticipate a series of important changes imposed by the ebbing of the tide, thus ensuring enough time to abandon the intertidal zone or to look for shelter. For fish species of rocky shores, that do remain intertidally at low tide, the maximum activity is usually synchronised with the high water phase of the tidal cycle when they can move and feed freely (Gibson 1982).

Many papers have already been presented describing the rhythmic activity of rocky intertidal species, espe- 
cially in the families Blenniidae and Gobiidae (Gibson 1965, 1967, 1969, 1970, 1971; Northcott et al. 1990; Northcott 1991) but, to our knowledge, none about syngnathids.

Nerophis lumbriciformis (Jenyns, 1835) is a small and slender pipefish, commonly found in the rocky intertidal to about $30 \mathrm{~m}$ (Wheeler 1969; Dawson 1986), reaching a total length of $14 \mathrm{~cm}$ in males and $15 \mathrm{~cm}$ in females. It feeds on small crustaceans (copepods, amphipods, and isopods), sucking them through its snout, characteristically pointed upwards. Its distribution ranges from the Atlantic coast of Norway to the Kattegat, and from Belgium southwards to Morocco (Dawson 1986). During the breeding season, males brood their offspring attached to their flattened ventral surface (Monteiro et al. 2001). Throughout gestation parental care is exclusively paternal (Monteiro et al. 2002). The newborn juveniles are free swimming and no further care is provided.

Curiously there is almost no information about the ecology or behaviour of this pipefish species, especially near its southern geographical limit of distribution. We predicted that $N$. lumbriciformis, as an intertidal inhabitant, would show a clear rhythmic activity, with its maximum closely correlated with the high tide period as observed in several other rocky intertidal fish species. In this article, the rhythmic activity of $N$. lumbriciformis was investigated. In addition, because preliminary observations showed that $N$. lumbriciformis occupied algae or spaces under boulders, we analysed to what extent this shift in microhabitats may be linked to water level and, ultimately, to the activity rhythm patterns of the fish.

\section{Methods}

Fishes were caught by hand, in Viana do Castelo, Portugal $\left(41^{\circ} 41^{\prime} 45^{\prime \prime} \mathrm{N}, 8^{\circ} 51^{\prime} 09^{\prime \prime} \mathrm{W}\right)$, during spring tides (summer and winter), without the use of anaesthetic. Different individuals were used in each of the various rhythm and substratum experiments. Due to the "gas bubble disease", common in pipefishes, aeration was performed in an external aquarium connected to the aquaria used in the several experiments.

\section{Substratum preferences}

To determine the substratum preferences of $N$. lumbriciformis, two distinct, interdependent experiments were conducted. The first experiment was designed to evaluate the substratum preferences of $N$. lumbriciformis from among a group of four representative alternatives (algae, flat rock, sand, and boulders - the four most common substrata found in the sample area). The second experiment was designed to evaluate the maintenance of substratum preference after alteration of the water level in a simulated ebb tide.

\section{Experiment 1}

An aquarium containing approximately 3001 of circulating seawater $\left(15^{\circ} \mathrm{C}\right)$ was divided into four identical areas (approximately $1,500 \mathrm{~cm}^{2}$ each), equally distant from a central point at which the fishes were released. These sections were composed of:
- Algae (several species were brought from the same location where the fish were collected, for example, Saccorhiza polyschides, Laminaria hyperborea, Bifurcaria bifurcata, Sargassum muticum, Codium tomentosum, Osmundia pinatifida, Gelidium sesquipedale, and Corallina officinalis)

- Flat rock (flat rock bottom surface, without any available shelter)

- Sand (regular sand bottom surface, also without any available shelter)

- Boulders (irregular rock bottom surface, with a great amount of crevices where fishes could easily hide)

The algae were anchored on sand either directly or in a small pot that was buried in the substratum.

A total of 18 individuals were used. Fishes were slowly introduced into the aquarium from a holding tank, inside an opaque semi-cylinder, and allowed to rest for approximately $5 \mathrm{~min}$. If the fish presented any evident stress behaviour, this period was extended until its apparent recovery. Otherwise, the cylinder was slowly retracted and the substratum choice of the fish recorded. The position of the four substratum alternatives was reordered after each trial.

Differences in substratum choices were determined using ADERSIML (Almada and Oliveira 1997). This computer program implements a procedure to access the significance of goodness of fit tests that would usually be addressed using the $\chi^{2}$ distribution. This procedure was chosen because it allows the analysis of data where expected frequencies are very low (less than 4 or even 0 ) in several classes, a condition in which the $\chi^{2}$ distribution must not be used (Zar 1984). The procedure generates 1,000 simulations each with the same number of cases equal to the sum of all observed frequencies. Each case is randomly assigned to one of the classes with probabilities equal to the expected frequencies of each class. A $\chi^{2}$ square is computed for the simulated data set and the frequency of each class is compared with the expected frequency of that class. The number of times out of 1,000 that the $\chi^{2}$ of the simulations is equal to or greater than the $\chi^{2}$ computed for the actual data provides the direct assessment of the significance of that $\chi^{2}$. If, for instance, the $\chi^{2}$ of the original data was equal or exceeded only 20 times out of 1,000 , it would be concluded that the $\chi^{2}$ of the data was significant at $P<0.05$.

\section{Experiment 2}

In an aquarium containing approximately 901 of circulating seawater $\left(15^{\circ} \mathrm{C}\right)$, two substrata (algae and boulders) with identical areas (approximately $800 \mathrm{~cm}^{2}$ each) were laid at the same distance from a central point at which all the fishes were released. Substrata disposition was altered between each trial. Fishes were introduced into the aquarium inside a transparent box and released only after they turned their heads to both substratum alternatives. Ten individuals (non-pregnant males and females) were used separately. Once the transparent box was retracted, a 30-min observation period started after which the fish position was recorded. The water level inside the aquarium (approximately $35 \mathrm{~cm}$ ) was then slowly reduced over $30 \mathrm{~min}$ to a depth of approximately $1 \mathrm{~cm}$, thus simulating the ebb of the tide. The alteration of the substratum choice was determined using ACTUS2 (Estabrook and Estabrook 1989), a statistical technique using the $\chi^{2}$ distribution for analysing contingency tables. To determine consistency of the observed counts with a hypothesis that the rows and columns are independent, ACTUS2 simulates tables that are examples of the sorts of tables of counts that would arise if the rows and columns were truly independent. By simulating a large number of tables (often 1,000 or even more), it is possible to get an idea of how often the observed counts would have occurred under the hypothesis of independence. Results of these simulations are presented in two tables, each with as many rows and columns as the observed table. One table identifies boxes in the observed table that have a smaller number of cases than would be predicted by the hypothesis of independence. The other table identifies boxes in the observed table 
that have a larger number of cases than would be predicted by the hypothesis of independence. ACTUS2 then calculates the value of $\chi^{2}$ for every simulated table and compares it to the value calculated from the observed table. The fraction of simulated tables with values greater than or equal to the observed value estimates the realised significance of the observed $\chi^{2}$ value. ACTUS2 reports this fraction, which depends on the hypothesis used to simulate the tables. If our entire table does not differ significantly from what would be predicted under the specified hypothesis of independence, then we are not warranted to interpret any of the boxes indicated by the produced tables.

\section{Rhythmic activity}

The captured fish were transported from the beach to the laboratory in a holding tank, for about $1-2 \mathrm{~h}$, and inserted in the recording chamber, where they were allowed to rest for approximately $1 \mathrm{~h}$ prior to the beginning of the experiment. Because $N$. lumbriciformis is a relatively inactive species, causing individual recordings to produce almost unrecognisable patterns, groups of five fish of the same gender were used in each experiment. Water flowed continuously through the aquarium, maintaining a constant temperature of $15^{\circ} \mathrm{C}$. The tanks were continuously illuminated with $18-\mathrm{W}$ fluorescent light. Fish were not fed during the experiments, because it could interfere with their activity levels, as observed by Gibson $(1967,1971)$ for Lipophrys pholis. The activity of each group was recorded with a surveillance camera attached to a Sony video recorder (which allowed continuous 24-h filming to be recorded on a 3-h VHS tape). Four imaginary lines, established $a$ priori, were drawn on a TV monitor. One movement was scored each time a fish intercepted one of these lines. The movement registration was performed with a 15-min interval (shorter intervals tended to increase the background noise whereas longer intervals obstructed the detection of the underlying period). For L. pholis, a strongly rhythmic species, the persistence of the circatidal rhyth- micity is visible for at least 4 days (Gibson 1967). For other intertidal fish species that share with $N$. lumbriciformis the same vertical distribution (Gibson 1972), the rhythm's persistence tends to be even shorter (Gibson 1965, 1967). Thus, all experiments lasted 4 days. Experiments with individuals maintained in aquarium for several months were also undertaken.

The analysis of time series of biological data often requires special statistical procedures to test for the presence or absence of rhythmic components in noisy data (Ruf 1999). Therefore, as suggested by Legendre and Dutilleul (1992), periodograms and autocorrelograms were constructed for each experiment. Both techniques are used to search for periodicity in a time series by comparing measurements separated by a range of time intervals. The autocorrelogram evaluates the correlation of each data series to itself separated by a given time lag that is systematically varied. If, for instance, the pairs of points separated by $12 \mathrm{~h}$ show higher correlation values than other sets of pairs of points separated by different time lags, this provides an indication that a cycle with a period of $12 \mathrm{~h}$ may be present in the data. If a cycle persists with decreasing amplitude as time passes, the autocorrelogram may not be able to detect the cyclic pattern. Thus we decided to use periodograms as a complementary tool since they depend less on the absolute values at different points of the data and more on the topology of the data series curve.

Fig. 1 An example of the typical activity rhythm of Nerophis lumbriciformis, recorded in constant conditions (A). The expected day, night, and crepuscular periods are represented, as well as the expected times of high tide $(H T)$ and low tide $(L T)$. The respective periodogram (B) and autocorrelogram $(\mathbf{C})$ are also presented (note that the time lags represented in $\mathbf{B}$ and $\mathbf{C}$ do not represent time periods measured starting with a specific event, like the time of day or phase of the tidal cycle, but a succession of increasingly larger intervals used in the statistical analysis of the data series)

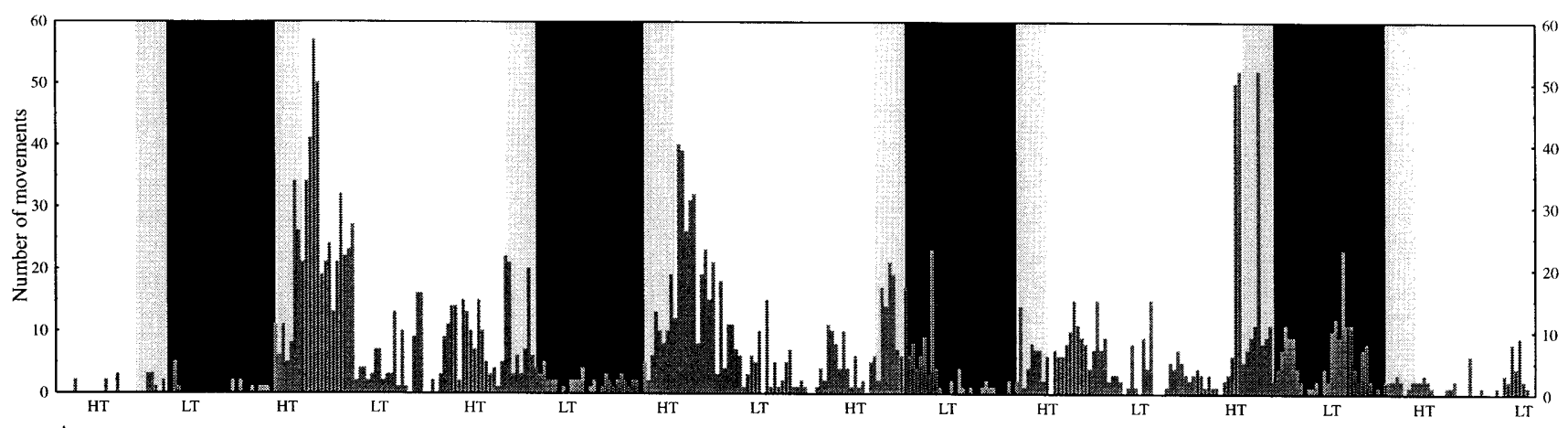

A
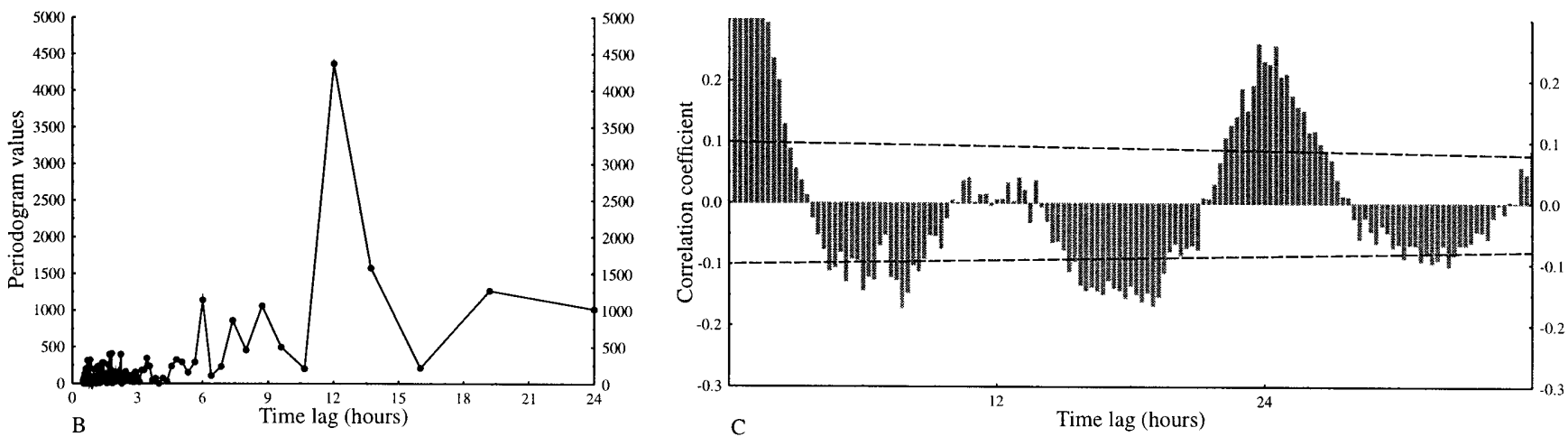
Using values from the experiments conducted with freshly caught individuals, the activity patterns (tidal activity and diurnal/nocturnal activity) were analysed by two-way repeated measures ANOVA for both factors, after checking the normality of the data (Kolmogorov-Smirnov test). Values used $(n=8)$ consisted of the average activity recorded throughout the ebbing and filling of the tide, during both the day and night.

\section{Results}

\section{Substratum preferences}

In the first substratum experiment, $N$. lumbriciformis displayed a clear preference for algae $\left(\chi^{2}=34, d f=3, P<0.01\right.$; algae $=15$, rock $=3$, sand and boulders $=0)$. In the second experiment $N$. lumbriciformis showed a distinct preference for algae (8:2). However, once the water level started to descend (simulating the ebb of the tide), its preference radically changed $(0: 10)\left(\chi^{2}=13.333, P<0.01\right)$, with all individuals ending up in the boulder section. This displacement was preceded by an increase in activity. All the fish started a series of exploratory movements, even if they were already underneath the boulders. Without exception, every fish ended up in the boulder section of the aquarium.

\section{Rhythmic activity}

We found a significant difference among diurnal/nocturnal activity (repeated measures ANOVA; data log transformed; Cochran's $C=0.403, P=0.547)(F(1,9)=12.319$; $P<0.01)$ and tidal activity $(F(1,9)=10.378 ; P<0.01)$, but no interaction between the two factors $(F(1,10)=2.227$; $P>0.05)$.

The analysis of the several autocorrelograms corroborated these results showing a clear circadian periodicity (24- to 25-h period) that resulted from the asymmetric day and night movement frequency (Fig. 1C). In three out of four experiments conducted with individuals that were kept in aquaria for several months, this periodicity was still clearly visible, suggesting that light and darkness are responsible for maintaining this circadian period. On the other hand, the periodogram analysis showed the presence of a 12- to 13 -h period (Fig. 1B). This kind of periodicity suggests the presence of a circatidal period. Nevertheless, this circatidal rhythmicity seems to depend on the time of day that the second tide occurs. If it occurs during the night, the night-time tidal peaks are almost suppressed, with only the circadian period remaining visible (data not shown). When two activity peaks were visible during the day, the first was clearly higher than the second.

\section{Discussion}

The distribution of $N$. lumbriciformis in the intertidal zone is often misinterpreted or insufficiently described.
It is common to see in many field guides that "these fishes live beneath the stones, even though they resemble intertidal algae" (e.g. Wheeler 1978; Rodriguez et al. 1995; Miller and Loates 1997). Such descriptions of the habitat of $N$. lumbriciformis reflect the fact that most observations were made during low tide. Nevertheless, most of the time, the lower part of the shore is submerged, and the distribution of this species is quite different. In fact, during high tide $N$. lumbriciformis can be found among intertidal seaweeds (personal observation). Its morphology, behaviour, and coloration, at least to a human observer, make the fish very difficult to detect among algae, probably protecting it from potential predators and allowing a close approach from its prey.

Boulders seem, however, equally important for the settlement of $N$. lumbriciformis populations along the coast. Arruda (1990), in a work concerning the structure of the intertidal fish communities in Portugal, described the presence of this species in three of five locations sampled. These three locations, unlike the others, presented numerous loose stones in the intertidal zone.

The substratum experiments clearly confirmed the preference of $N$. lumbriciformis for algae. At the same time, they also showed that the fish responded to a reduction in water level by seeking refuge among boulders (an interstitial microhabitat where shelter is available and temperature and humidity are presumably more stable than at exposed rock).

We suggest that a major function of the activity rhythms of $N$. lumbriciformis may be to ensure adequate timing of the shift between the algal microhabitat of high tide and the interstitial microhabitat used during low tide. As syngnathids are visual feeders (Bergert and Wainwright 1997), the suppression of activity peaks during the night also makes sense in this scenario since the fish would gain little or no benefit by moving to the algae when they cannot feed.

The activity rhythms (both circatidal and circadian) remained detectable in the absence of the most obvious zeitgebers, such as light, temperature, and tidal fluctuations (see Gibson 1967), in some cases for the total duration of the experiment (4 days), providing strong evidence for the presence of internal components for both rhythms. The presence of two distinct internal clocks involved in circatidal and circadian rhythms has already been postulated in studies of other intertidal fish species (Gibson 1969, 1970, 1971).

Finally, we would like to comment on a methodological issue that emerged in the present study. The rhythmic activity of $N$. lumbriciformis produced asymmetrical peaks as described for Coryphoblennius galerita (Gibson 1970), Parablennius gattorugine and P. sanguinolentus (Gibson 1969). This phenomenon is to be expected when circadian and circatidal rhythms are operating simultaneously. In these situations periodograms and autocorrelograms produce somewhat different pictures. In our study, the periodogram especially emphasised the presence of the circatidal rhythm, whilst the autocorrelogram primarily detected the circadian rhythmicity. This 
fact is probably due to the asymmetry between the two tidal activity peaks. Because two consecutive peaks have different amplitudes, the correlation of a series of values with itself, within a 12- to 13-h lag, is relatively small although the circatidal rhythmicity exists. Periodograms seem to be much more sensitive to circatidal rhythms with asymmetrical peaks although they are also more sensitive to the presence of background noise. Thus, the combined use of these particular statistical tools, in cases such as this, seems to facilitate the interpretation of the results.

Acknowledgements We would like to thank Prof. Alexandre Valente for lending us the video recording material; Sandra Quinteira and Pedro Correia for all the assistance granted during the recording phase and João Bacelo for suggestions made during the early phases of this work. Prof. Vitor Almada's participation was partially funded by Programa Plurianual de Apoio às Unidades de Investigação and CLIPE (PRAXIS 3/3.2/EMG/1957/95). Nuno Monteiro's participation was funded by Fundação para a Ciência e Tecnologia (SFRH/BD/2747/2000). All experiments comply with the Portuguese legislation.

\section{References}

Almada VC, Oliveira RF (1997) Sobre o uso de estatística de simulação em estudos de comportamento. Anál Psicol 1(15): 97-109

Arruda LM (1990) Population structures of fish in the intertidal ranges of the Portuguese coasts. Vie Milieu 40(4):319-323

Bergert BA, Wainwright PC (1997) Morphology and kinematics of prey capture in the syngnathid fishes Hippocampus erectus and Syngnathus floridae. Mar Biol 127:563-570

Dawson CE (1986) Syngnathidae. In: Whitehead PJP, Bauchot ML, Hureau JC, Nielsen J, Tortonese E (eds) Fishes of the north-eastern Atlantic and the Mediterranean. UNESCO, Paris, pp 628-639

Estabrook CB, Estabrook GF (1989) ACTUS: a solution to the problem of small samples in the analysis of two-way contingency tables. Hist Methods 22:5-8

Gerkema MP (1992) Biological rhythms: mechanisms and adaptative values. In: Ali MA (ed) Rhythms in fishes. (NATO-ASI series A, vol 236) Plenum Press, New York, pp 27-37

Gibson RN (1965) Rhythmic activity in littoral fish. Nature 207(4996):544-545

Gibson RN (1967) Experiments on the tidal rhythm of Blennius pholis. J Mar Biol Assoc UK 47:97-111

Gibson RN (1969) Activity rhythms in two species of Blennius from the Mediterranean. Vie Milieu 20:235-244

Gibson RN (1970) The tidal rhythm of activity of Coryphoblennius galerita (L.) (Teleostei, Blenniidae). Anim Behav 18:539_ 543
Gibson RN (1971) Factors affecting the rhythmic activity of Blennius pholis L. (Teleostei). Anim Behav 19:336-343

Gibson RN (1972) The vertical distribution and feeding relationship of intertidal fish on the Atlantic coast of France. J Anim Ecol 41:189-207

Gibson RN (1982) Recent studies on the biology of intertidal fishes. Oceanogr Mar Biol Annu Rev 20:363-414

Gibson RN (1988) Patterns of movement in intertidal fishes. In: Chellazi G, Vannini M (eds) Behavioural adaptation to intertidal life. Plenum Press, New York, pp 55-63

Gibson RN (1992) Tidally-synchronised behaviour in marine fishes. In: Ali MA (ed) Rhythms in fishes. (NATO-ASI series A, vol 236) Plenum Press, New York, pp 63-81

Gibson RN (1993) Intertidal teleosts: life in a fluctuating environment. In: Pitcher TJ (ed) Behaviour of teleost fishes. Chapman \& Hall, London, pp 513-536

Gibson RN (1999) Movement and homing in intertidal fishes. In: Horn MH, Martin KLM, Chotkowski MA (eds) Intertidal fishes. Life in two worlds. Academic Press, San Diego, pp 97-125

Leatherland J F, Farbridge KJ, Boujard T (1992) Lunar and semilunar rhythms in fishes. In: Ali MA (ed) Rhythms in fishes. (NATO-ASI series A, vol 236) Plenum Press, New York, pp 83-107

Legendre P, Dutilleul P (1992) Introduction to the analysis of periodic phenomena. In: Ali MA (ed) Rhythms in fishes. (NATO-ASI series A, vol 236) Plenum Press, New York, pp 11-25

Miller PJ, Loates MJ (1997) Fish of Britain \& Europe. Harper Collins, London

Monteiro NM, Almada VC, Santos AM, Vieira MN (2001) The breeding ecology of the pipefish Nerophis lumbriciformis and its relation to latitude and water temperature. J Mar Biol Assoc UK 81(6): 1031-1033

Monteiro NM, Vieira MN, Almada VC (2002) The courtship behaviour of the pipefish Nerophis lumbriciformis: reflections of an adaptation to intertidal life. Acta Ethol 4:109-111

Naylor E (1988) Clock-controlled behaviour in intertidal animals In: Chellazi G, Vannini M (eds) Behavioural adaptation to intertidal life. Plenum Press, New York, pp 1-14

Northcott SJ (1991) A comparison of circatidal rhythmicity and entrainment by hydrostatic pressure cycles in the rock goby, Gobius paganellus L. and the shanny, Lipophrys pholis (L.). J Fish Biol 39:25-33

Northcott SJ, Gibson RN, Morgan E (1990) The persistence and modulation of endogenous circatidal rhythmicity in Lipophrys pholis (Teleostei). J Mar Biol Assoc UK 70:815-827

Rodriguez XL, Vázquez X, Escudero HA (1995) Peixes do mar de Galicia, vol III. Edicións Xerais de Galicia, Vigo, Spain

Ruf T (1999) The lomb-scargle periodogram in biological rhythm research: analysis of incomplete and unequally spaced timeseries. Biol Rhythm Res 30(2):178-201

Wheeler A (1969) The fishes of the British Isles and north west Europe. Macmillan, London

Wheeler A (1978) Key to the fishes of northern Europe. Frederick Warne, London

Zar JH (1984) Biostatistical analysis. Prentice-Hall, Upper Saddle River, N.J. 